\title{
Avaliação de rações de alta densidade nutricional para porcas em lactação no verão ${ }^{1}$
}

\author{
Douglas Haese ${ }^{2}$, Juarez Lopes Donzele ${ }^{3}$, Rita Flávia Miranda de Oliveira ${ }^{3}$, João Luís Kill ${ }^{2}$, \\ Francisco Carlos de Oliveira Silva ${ }^{4}$, Fabrício de Almeida Santos ${ }^{5}$, Márvio Lobão Teixeira \\ de Abreu $^{6}$
}

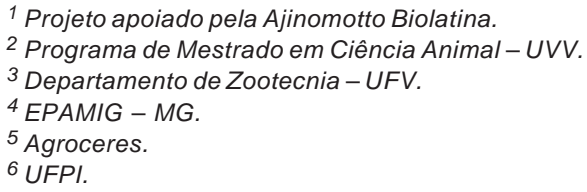

RESUMO - Para avaliar dietas de alta densidade nutricional, com ou sem suplementação de aminoácidos industriais, ajustadas com base na energia líquida, utilizaram-se 80 porcas pluríparas, em lactação, do mesmo padrão genético, distribuídas em delineamento experimental de blocos composto por quatro dietas, 20 blocos, considerando cada porca uma unidade experimental. Na formação dos blocos, utilizaram-se como critérios o peso e a ordem de parto das porcas. As dietas foram formuladas com a combinação de quatro níveis de proteína bruta (18,33; 15,23; 19,63; ou 16,59\%), quatro de energia metabolizável (3.344; 3.293; 3.480; e $3.440 \mathrm{kcal} / \mathrm{kg}$ ), dois de lisina digestível (0,85 e 0,95\%) e dois de energia líquida (2.519 e 2.636 kcal de EL/kg) e da suplementação com aminoácidos industriais até a relação triptofano:lisina digestíveis de 18\%. Não houve efeito das dietas com alta densidade nutricional, com ou sem suplementação de aminoácidos, sobre o consumo médio diário de ração. As dietas também não influenciaram o peso, a perda e variação de peso, o intervalo desmama-estro nem a estimativa da produção de leite das porcas no período de lactação. Dietas de alta densidade nutricional (lisina e energia) para porcas em lactação são eficientes em reduzir a mobilização de reservas corporais e não afetam os desempenhos produtivo e reprodutivo das porcas.

Palavras-chave: energia, estro, leitões, óleo, peso, temperatura

\section{Evaluation of rations with high nutritional density rations for lactation sows during the summer}

\begin{abstract}
In order to evaluate diets with high nutritional density, with or without industrial amino acid supplementation, adjusted at net energy base, it was used 80 pluriparous lactating sows with the same genetic pattern, distributed in an experimental block design composed of four diets, 20 blocks, considering each sow an experimental unity. The criteria used for formation of the blocks were the weight and parity order. Diets were formulated by the combination of four levels of crude protein $(18.33 ; 15.23 ; 19.63$; or $16.59 \%)$, four levels of metabolizable energy $(3,344 ; 3,293 ; 3,480$; and $3,440 \mathrm{kcal} / \mathrm{kg}$ ), two of digestible lysine (0.85 and $0.95 \%)$ and two levels of net energy (2,519 and 2,636 kcal of NE/kg) and the supplementation with industrial amino acids up to the digestible triptofano:lysine relationship of $18 \%$. There was no effect of the diets with high nutritional density, with or without amino acid supplementation, on the average daily intake of the ration. The diets did not influence weight, loss and changes on weight, the internal weaning-to-estrus interval neither the estimate of milk production of the sows during lactation period. Diets of high nutritional density (lisyne and energy) for lactating sows are efficient in reducing mobilization of body reserves and they do not affect productive and reproductive performance of the sows.
\end{abstract}

Key Words: energy, estrus, oil, piglets, temperature, weight

\section{Introdução}

Atualmente, as matrizes suínas são mais precoces, produzem mais leite, possuem maior peso corporal, têm menor capacidade de consumo e são mais exigentes nutricionalmente.
Entretanto, essas características obtidas pelo melhoramento genético predispõem as porcas a frequentes estádios de catabolismo durante a lactação, resultando na mobilização de tecidos devido à alta demanda por nutrientes, principalmente para a produção de leite (Mullan \& Williams, 1990). 
Vários estudos demonstraram que o baixo consumo de aminoácidos, principalmente lisina, ou energia durante a lactação pode resultar em redução do desempenho da leitegada e falhas reprodutivas subsequentes, sendo esse efeito mais pronunciado em porcas primíparas do que em multíparas, uma vez que tais animais ainda se encontram em fase de crescimento (Eissen et al., 2003). Avaliando diferentes relações treonina:lisina digestível, Oliveira et al. (2008) verificaram que matrizes suínas lactantes com perdas de peso de 3,6\% possuem exigência de $0,608 \%$ de treonina digestível na ração, que corresponde a uma relação de $64 \%$ com a lisina digestível, para manifestar os melhores resultados produtivos e reprodutivos.

Por outro lado, o consumo de ração pelas porcas durante a lactação pode ser insuficiente para satisfazer as exigências para produção de leite. Além disso, diversos fatores ambientais podem reduzir esse consumo (Gourdine et al., 2006).

Em regiões tropicais, a temperatura pode ser o principal fator ambiental envolvido na redução do consumo (Quiniou \& Noblet, 1999). Essa redução ocorre, frequentemente, quando a temperatura ambiental excede a zona de termoneutralidade, a qual pode variar entre 15 e $20^{\circ} \mathrm{C}$ (Black et al., 1993; De Bragança, et al., 1998). Assim, as porcas no verão quase sempre se encontram estressadas pelo calor, havendo, portanto, redução no consumo da dieta. Segundo Renaudeau et al. (2001), esse ajuste no consumo ocorre como tentativa do organismo reduzir a produção de calor proveniente do seu metabolismo.

Assim, o consumo adequado de nutrientes durante a lactação é fundamental para a síntese do leite e a manutenção do potencial reprodutivo subsequente das porcas (Spencer et al., 2003). Já a ingestão insuficiente de nutrientes pode resultar na mobilização de diferentes tecidos corporais, aumentando o intervalo desmame-cio e, consequentemente, os dias não produtivos das porcas.

Torna-se importante, então, o estudo das exigências nutricionais das porcas durante a lactação, haja vista que a excessiva mobilização das reservas corporais reduz a produção de leite e a fertilidade subsequente da porca. Este trabalho foi conduzido com o objetivo de avaliar dietas de alta densidade nutricional, ajustadas com base na energia líquida, com ou sem suplementação de aminoácidos industriais, para porcas em lactação durante o verão, considerando os desempenhos produtivos e reprodutivos.

\section{Material e Métodos}

O experimento foi conduzido, entre os meses de dezembro e fevereiro de 2005, na Fazenda Água Limpa, localizada no município de Jequeri, em Minas Gerais.
Foram utilizadas oitenta porcas pluríparas, em lactação, do mesmo padrão genético, distribuídas em delineamento experimental de blocos ao acaso com quatro dietas, vinte blocos (repetições), sendo cada porca considerada uma unidade experimental. Na formação dos blocos, foram levados em consideração o peso e a ordem de parto das matrizes.

As dietas experimentais foram assim constituídas: ração com 18,33\% de PB, 3.344 kcal de EM/kg, 0,85\% de lisina digestível (LD) e 2.519 kcal de EL/kg; ração com 15,23\% de PB, $3.293 \mathrm{kcal}$ de EM/kg, 0,85\% de LD e $2.519 \mathrm{kcal} \mathrm{de} \mathrm{EL/kg,}$ suplementadas com aminoácidos industriais (AAI); ração com 19,63\% de PB, $3.480 \mathrm{kcal}$ de EM/kg, 0,95\% de LD e $2.636 \mathrm{kcal}$ de EL/kg, e ração com 16,59\% de PB, 3.440 kcal de EM/kg, 0,95\% de LD e $2.636 \mathrm{kcal}$ de EL/kg, suplementada com AAI até o limite da relação do triptofano digestível com a lisina digestível, de $18 \%$.

As dietas experimentais (Tabela 1) foram formuladas à base de milho, farelo de soja, farelo de trigo e suplementadas com minerais, vitaminas e aminoácidos industriais.

Após o parto, as porcas receberam as dietas experimentais e água à vontade, durante todo o período experimental. As sobras das dietas do comedouro foram coletadas após as refeições e pesadas para avaliar o consumo diário voluntário.

As porcas foram pesadas 24 horas após o parto e ao final da lactação. As leitegadas foram pesadas após o nascimento e equalizadas em 12 leitões/porcas, até 72 horas pós-parto. Os leitões receberam o manejo tradicional da granja (corte de dentes e cauda, cura de umbigo e marcação) até 24 horas após o nascimento. Após o desmame os leitões foram novamente pesados e encaminhados para o setor de creche e as porcas para o setor de gestação, onde foram alojadas em gaiolas individuais e alimentadas com 3,0 kg de dieta de lactação/porcas/dia, distribuídas em duas refeições.

A temperatura, no interior do galpão, foi registrada por meio de termômetros de máxima e mínima, sendo realizada diariamente, às 8:00 horas, durante todo o período experimental.

No período entre o desmame e a cobertura subsequente, procedeu-se o acompanhamento do retorno ao estro, todos os dias, pela manhã, levando-se o cachaço até a baia das porcas. Foram consideradas em estro as porcas que permaneceram imóveis à monta (reflexo de tolerância ao macho - RTM - positivo).

As variáveis de desempenho foram analisadas pelo Sistema de Análises Estatísticas e Genéticas (SAEG), desenvolvido pela Universidade Federal de Viçosa (UFV, 2000), versão 8.0, utilizando-se os procedimentos para análises de variância. Foi usado o teste Student-Newman-Keuls (SNK) 
Tabela 1 - Composição em ingrediente e nutricional das dietas experimentais

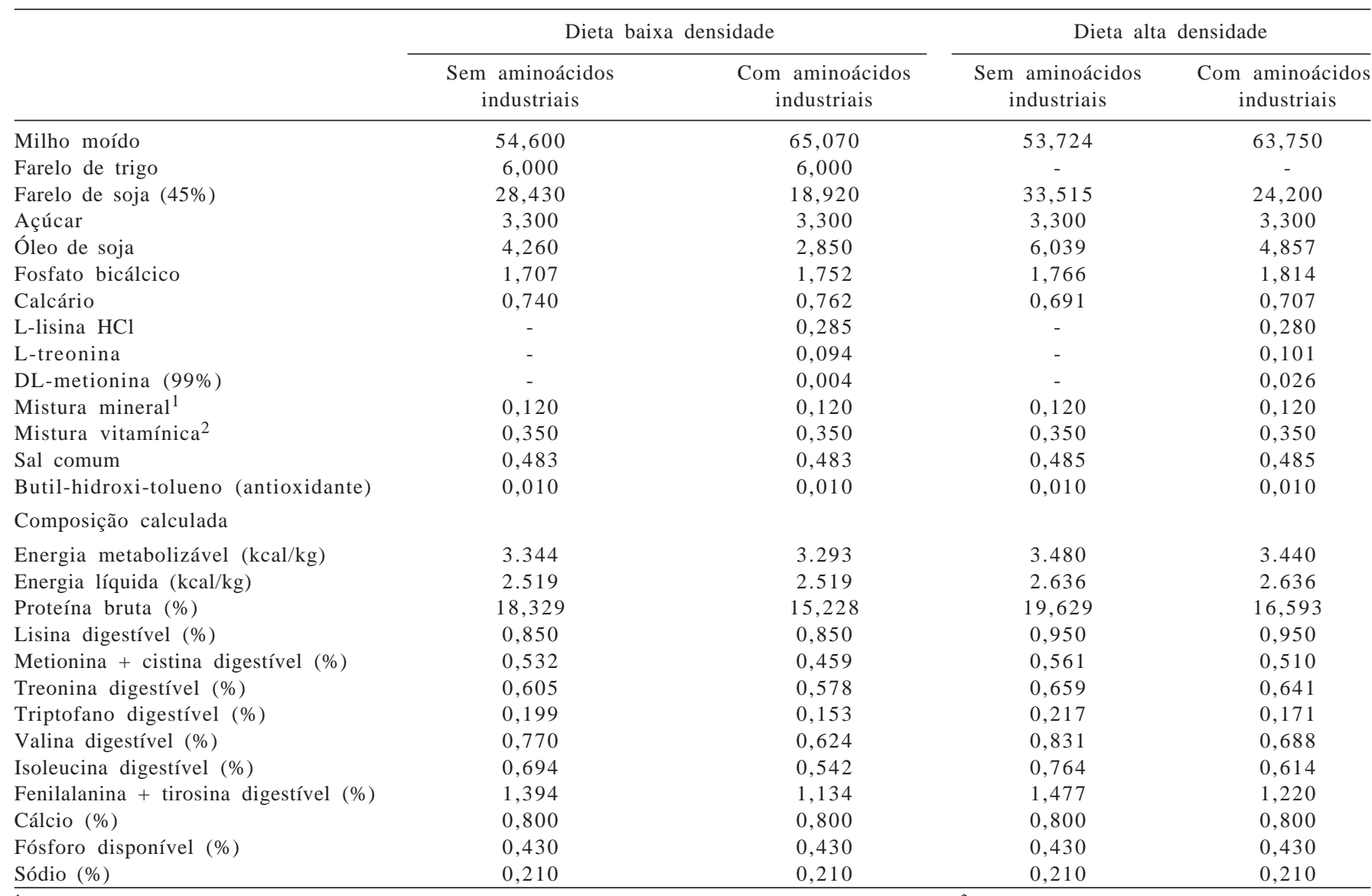

${ }^{1}$ Composição por kg do produto: Fe - 180 g; Cu - 20 g; Co - 4 g; Mn - 80 g; Zn - 140 g; I - 4 g; e excipiente q.s.p. - 1.000 g. ${ }^{2}$ Composição por kg do produto: vit. A - 12.000 .000 UI; vit. D3 - 1.500.000 UI; vit. E - 8.000 UI; vit. K3 - 4 g; vit. B2 - 4 g; vit. B6 - 5 g; vit. B12 - 30.000 mg; ácido nicotínico - 40 g; ácido pantotênico - 20 g; bacitracina de zinco - $10 \mathrm{~g}$; antioxidante - $30 \mathrm{~g}$; e excipiente q.s.p. - $1.000 \mathrm{~g}$.

para testar os contrastes entre as médias dos tratamentos para cada variável avaliada. Para o peso do leitão ao nascimento e a variação do peso da porca na lactação, foram utilizados, respectivamente, como covariáveis o número de nascidos totais e o consumo de ração na lactação.

\section{Resultados e Discussão}

As médias das temperaturas registradas no termômetro de máxima e mínima foram, respectivamente, de 31,0 \pm 2,50 e $20,9 \pm 2,00^{\circ} \mathrm{C}$. Considerando que a zona de termoneutralidade para porcas em lactação, segundo Black et al. (1993) e De Bragança et al. (1998), está caracterizada por temperaturas entre $15^{\circ} \mathrm{C} \mathrm{e} 20^{\circ} \mathrm{C}$, constatou-se, com base na variação de temperatura ocorrida durante o período experimental, que as porcas foram submetidas a períodos de estresse por calor.

Não houve efeito $(\mathrm{P}>0,05)$ no consumo das dietas contendo diferentes densidades de lisina e energia, que foi em média de 5,85 kg/dia (Tabela 2).
Resultados semelhantes foram obtidos por Dourmad et al. (1998) e Paiva et al. (2004), que não constaram, respectivamente, influência do aumento do nível de lisina e energia sobre o consumo de dietas de porcas durante a lactação. Em contrapartida, Richert et al. (1997), conduzindo estudos para avaliar o efeito dos níveis de lisina e valina durante a lactação, verificaram variação no consumo de dieta pelos animais.

Tabela 2 - Consumo médio diário de ração e de lisina digestível de porcas no período de lactação alimentadas com rações de alta e baixa densidade de aminoácidos

\begin{tabular}{lcc}
\hline Tratamentos & $\begin{array}{c}\text { Ração } \\
\text { (kg/dia) }\end{array}$ & $\begin{array}{l}\text { Lisina } \\
\text { (g/dia) }\end{array}$ \\
\hline Baixa densidade sem aminoácidos industriais & 5,89 & $50,01 \mathrm{~b}$ \\
Baixa densidade com aminoácidos industriais & 5,82 & $49,47 \mathrm{~b}$ \\
Alta densidade sem aminoácidos industriais & 5,93 & $56,34 \mathrm{a}$ \\
Alta densidade com aminoácidos industriais & 5,75 & $54,63 \mathrm{a}$ \\
CV (\%) & 10,64 & 10,60 \\
\hline
\end{tabular}

${ }^{1}$ Média seguidas de letras diferentes, na mesma linha, diferem entre si pelo teste de Student Newman Keuls. 
O consumo diário de lisina aumentou $(\mathrm{P}<0,05)$ conforme o consumo de ração. Como o consumo das dietas não variou entre si, o aumento no consumo de lisina ocorreu em razão direta de sua concentração nelas.

Assim, as porcas que receberam dietas contendo 0,95\% de lisina digestível, suplementadas ou não com aminoácidos industriais, apresentaram maiores $(\mathrm{P}<0,05)$ consumos de lisina (56,34 e 54,63 g/dia, respectivamente) em relação às que receberam dietas com $0,85 \%$ de lisina digestível, com ou sem aminoácidos industriais (50,01 g/dia e 49,47 g/dia, respectivamente).

De acordo Touchette et al. (1998), a necessidade de lisina digestível estimada para um bom crescimento da leitegada é de $27 \mathrm{~g}$ /dia e a necessidade diária para minimizar a mobilização de proteína corporal, de 46,5 g. Segundo Tokach et al. (1992), a exigência de lisina para minimizar a perda de massa muscular durante a lactação e melhorar o desempenho reprodutivo subsequente é mais alta que a exigência para produção de leite e desenvolvimento da leitegada.

O maior valor absoluto de perda de peso das porcas correspondeu a somente $2,46 \%$ do seu peso corporal (Tabela 3). Assim, pode-se inferir que o consumo de 50,01 g/dia de lisina digestível foi suficiente para garantir a produção de leite das porcas, sem a necessidade de uma mobilização expressiva de tecido corporal. Dessa forma, o aumento no consumo de lisina pelas porcas que receberam dietas contendo $0,95 \%$ de lisina digestível em relação às que receberam dietas com $0,85 \%$ não influenciou de forma significativa $(\mathrm{P}>0,05)$ a perda de peso das porcas. Entretanto, pode-se observar que as porcas que consumiram dietas contendo $0,85 \%$ de lisina digestível sem ou com suplementação de aminoácidos industriais apresentaram, em valores absolutos, 6,0 e 4,5 kg de perda de peso, enquanto que as porcas que consumiram dietas com $0,95 \%$ de lisina digestível sem ou com suplementação de aminoácidos industriais perderam apenas 1,30 e 1,75 kg, respectivamente.
Possivelmente, o alto coeficiente de variação (233\%) tenha contribuído para que a perda de peso das porcas em lactação não tenha variado de forma significativa em função das dietas experimentais. Esses resultados estão consistentes com os dados de King \& Brown (1993), que estudaram a mobilização de proteína corporal de porcas em lactação e notaram que o consumo de lisina diário de $48 \mathrm{~g}$ foi suficiente para evitar a perda de peso dos animais. Com base em informações desses autores, o aumento da concentração de lisina na dieta de porcas em lactação é necessário quando o consumo voluntário dos animais está comprometido, o que ocorre normalmente em situações de alta temperatura ambiental.

Os resultados obtidos por Paiva et al. (2004), em que a perda de proteína corporal de porcas primíparas durante a lactação reduziu de $8,3 \%$ para $4,6 \%$, quando o consumo de lisina digestível aumentou de 36 para 45 g/dia, confirma a proposição de que a resposta das porcas ao consumo de lisina durante a lactação torna-se mais significativa em situação em que o consumo é baixo.

Os dados permitiram inferir, ainda, que a suplementação de aminoácidos industriais com concomitante redução do nível de proteína bruta da dieta possibilitou a redução de 1,4 e 1,2 kg de óleo de soja, respectivamente, nas dietas com 0,85 e 0,95\% de lisina digestível, sem comprometimento do aporte de energia líquida para os animais. Esse resultado está diretamente relacionado ao fato de as dietas suplementadas com aminoácidos industriais proporcionarem menor incremento calórico, sendo também um aspecto favorável em situação de alta temperatura.

Não houve $(\mathrm{P}>0,05)$ efeito das dietas sobre o número de dias para retorno ao estro das porcas após o desmame. Considerando o relato de Prunier et al. (1993) de que as porcas podem perder de 10 a $15 \%$ do peso corporal durante a lactação sem que haja redução do desempenho reprodutivo,

Tabela 3 - Peso, perda de peso e variação de peso, intervalo demama-estro e estimativa da produção de leite das porcas durante o período de lactação

\begin{tabular}{|c|c|c|c|c|c|}
\hline \multirow[t]{2}{*}{ Item } & \multicolumn{4}{|c|}{ Dieta } & \multirow[t]{2}{*}{$\mathrm{CV}(\%)$} \\
\hline & $\begin{array}{l}\text { Baixa densidade sem } \\
\text { aminoácidos industriais }\end{array}$ & $\begin{array}{l}\text { Baixa densidade com } \\
\text { aminoácidos industriais }\end{array}$ & $\begin{array}{c}\text { Alta densidade sem } \\
\text { aminoácidos industriais }\end{array}$ & $\begin{array}{l}\text { Alta densidade com } \\
\text { aminoácidos industriais }\end{array}$ & \\
\hline Número de porcas & 20 & 20 & 20 & 20 & -- \\
\hline \multicolumn{6}{|l|}{ Peso da porca (kg) } \\
\hline Pós-parto & 244,05 & 232,05 & 239,10 & 234,60 & 14,42 \\
\hline À desmama & 238,05 & 227,55 & 237,80 & 232,85 & 14,45 \\
\hline Perda de peso da porca (kg) & 6,00 & 4,50 & 1,30 & 1,75 & 233,17 \\
\hline Variação de peso (\%) & $-2,46$ & $-1,94$ & $-0,54$ & $-0,75$ & 245,15 \\
\hline Intervalo desmama-estro (dias) & 3,62 & 3,99 & 4,15 & 4,84 & 44,17 \\
\hline Produção de leite $(\mathrm{kg} / \text { porca/dia })^{1}$ & 10,18 & 9,85 & 9,81 & 9,90 & 25,89 \\
\hline
\end{tabular}

${ }^{1}$ Produção de leite $(\mathrm{g} /$ dia $)=7+$ [2,5 × ganho de peso médio do leitão $\left.(\mathrm{g})\right]+[80,2 \times$ peso inicial do leitão $(\mathrm{kg})] \times$ número de leitões. $($ Noblet $\&$ Etienne, 1989$)$. 
o baixo valor médio de 4,15 dias para o retorno ao estro das porcas após o desmame está coerente com a reduzida perda de peso (média de 1,42\%) constatada nos animais que consumiram as diferentes dietas experimentais.

As dietas experimentais não influenciaram $(\mathrm{P}>0,05)$ as variáveis avaliadas (Tabela 4). Apesar das diferenças no consumo de lisina pelas porcas, não se verificou variação $(\mathrm{P}>0,05)$ no ganho de peso diário dos leitões.

O valor médio de $200 \mathrm{~g} /$ dia de ganho de peso dos leitões durante o período de lactação foi semelhante aos obtidos por Paiva et al. (2004) e Dourmad et al. (2003), de, respectivamente, 197 e $209 \mathrm{~g} / \mathrm{dia}$, sendo superior ao valor médio determinado por Cota et al. (2003), de $188 \mathrm{~g} / \mathrm{dia}$, e inferior ao encontrado por Silva et al. (2004), de $257 \mathrm{~g} /$ dia.
De acordo com Jones \& Stahly (1999), o baixo consumo de nutrientes pelas porcas durante o período lactação aumenta a mobilização de tecidos corporais para satisfazer as exigências dos nutrientes destinados à produção de leite. Entretanto, esses mesmos autores relatam redução da proteína do leite de porcas alimentadas com dieta contendo baixo nível de proteína. Assim, sendo o leite, normalmente, a única fonte de nutrientes disponível para o leitão durante a lactação, a sua redução pode ter reflexos diretos sobre o ganho de peso dos leitões.

Dessa forma, a inconsistência de resultados constatada entre os trabalhos com relação ao ganho de peso dos leitões pode estar relacionada a fatores como nível de energia e proteína da ração, temperatura ambiental e ordem de parto das porcas.

Tabela 4 - Desempenho da leitegada equalizada, durante a lactação, de acordo com as dietas experimentais

\begin{tabular}{|c|c|c|c|c|c|}
\hline \multirow[t]{2}{*}{ Item } & \multicolumn{4}{|c|}{ Dieta } & \multirow[t]{2}{*}{ CV $(\%)$} \\
\hline & $\begin{array}{l}\text { Baixa densidade sem } \\
\text { minoácidos industriais }\end{array}$ & $\begin{array}{l}\text { Baixa densidade com } \\
\text { aminoácidos industriais }\end{array}$ & $\begin{array}{l}\text { Alta densidade sem } \\
\text { aminoácidos industriais }\end{array}$ & $\begin{array}{l}\text { Alta densidade com } \\
\text { aminoácidos industriais }\end{array}$ & \\
\hline Lactação (dias) & 17,14 & 17,80 & 17,05 & 17,30 & 11,82 \\
\hline Leitões equalizados & 11,50 & 11,40 & 11,45 & 11,55 & 5,97 \\
\hline Leitões desmamados & 10,55 & 10,15 & 10,55 & 10,85 & 10,51 \\
\hline \multicolumn{6}{|l|}{ Peso dos leitões (kg) } \\
\hline Ao nascer & 1,54 & 1,49 & 1,49 & 1,59 & 18,66 \\
\hline Ao desmame & 5,09 & 4,94 & 4,89 & 5,01 & 15,66 \\
\hline Ganho de peso (g/dia) & 207,1 & 193,8 & 199,4 & 197,7 & 17,76 \\
\hline \multicolumn{6}{|l|}{ Peso da leitegada (kg) } \\
\hline Ao nascer & 17,70 & 16,94 & 16,93 & 18,44 & 18,17 \\
\hline Ao desmame & 53,25 & 51,95 & 52,80 & 55,55 & 16,38 \\
\hline Ganho de peso da leitegada (kg/dia) & 35,55 & 35,01 & 35,87 & 37,11 & 18,29 \\
\hline
\end{tabular}

\section{Conclusões}

Dietas de alta densidade de lisina e energia, com ou sem suplementação de aminoácidos industriais, são eficientes em reduzir a mobilização de reservas corporais em porcas em lactação e permitem manter o desempenho produtivo e reprodutivo desses animais.

\section{Referências}

BLACK, J.L.; MULLAN, B.P.; LORSCHY, M.L. et al. Lactation in the sow during heat stress. Livestock Production Science, v.35, p.153-170, 1993.

COTA, T.S.; DONZELE, J.L.; OLIVEIRA, R.F.M. et al. Níveis de lisina em ração de lactação para fêmeas suínas primíparas. Revista Brasileira de Zootecnia, v.32, n.1, p.115-122, 2003.

DE BRAGANÇA, M.M.; MOUNIER, M.; PRUNIER, A. Does feed restriction mimic the effects of increased ambient temperatura in lactating sows? Journal of Animal Science, v.76, p.2017-2024, 1998.
DOURMAD, J.Y.; ETIENNE, M.; NOBLET, J. Effect of protein and lysine supply on performance, nitrogen balance, and body composition changes of sows during lactation. Journal of Animal Science, v.76, p.542-550, 1998.

EISSEN, J.J.; APELDOORN, E.J.; KANIS, E. et al. The importance of a high feed intake during lactation of primiparous sows nursing large litters. Journal of Animal Science, v.81, p.594-603, 2003.

GOURDINE, J.L.; BIDANEL, J.P.; NOBLET, J. et al. Effects of season and breed on the feeding behavior of multiparous lactating sows in tropical humid climate. Journal of Animal Science, v. 84, p.469-480, 2006.

JONES, D.B.; STAHLY, T.S. Impact of amino acid nutrition during lactation on body nutrient mobilization and milk nutrient output in primiparous sows. Journal of Animal Science, v.77, p.1513-1522, 1999.

KING, R.H.; BROWN, W.G. Interrelationships between dietary protein level, energy intake, and nitrogen retention in pregnant gilts. Journal of Animal Science, v.71, p.2450-2456, 1993.

MULLAN, B.P.; WILLIANS, I.H. The chemical composition of sows during their first lactation. Animal Production, v.51, p.375-387, 1990. 
NOBLET, J.; ETIENNE, M. Estimation of sow milk nutrient output. Journal of Animal of Science, v.67, p.3352-3359, 1989.

NOBLET, J.; ETIENNE, M.; DOURMAD, J.Y. Energetic efficiency of milk production. In: VERSTEGEN, M.W.A.; MOUGHAN, P.J.; SCHRAMA, J.W. (Eds.) The lactating sow. Wageningen: Wageningen Press, 1998. p.113-130.

OLIVEIRA, V.A.F.; DONZELE, J.L.; MLT ABREU, M.L.T. et al. Treonina digestível em rações para matrizes suínas em lactação. Revista Brasileira de Zootecnia, v.37, n.12, p.2141-2146, 2008.

PAIVA, F.P.; DONZELE, J.L.; OLIVEIRA, R.F.M. et al. Lisina em rações para fêmeas suínas primíparas em lactação. In: CONGRESSO LATINO-AMERICANO DE SUINOCULTURA, 2., 2004. Foz do Iguaçu, PR. Anais... Foz do Iguaçu, 2004. p.396.

PRUNIER, A.; DOURMAD, J.Y.; ETIENNE, M. Feeding level, metabolic parameters and reproductive performance of primiparous sows. Livestock Production, v.37, p.185-196, 1993.

QUINIOU, N.; NOBLET, J. Influence of high ambient temperature on performance of multiparous lactating sows. Journal of Animal Science, v.77, p.2124-2134, 1999.

RENAUDEAU, D.; QUINIOU, N.; NOBLET, J. Effects of exposure to high ambient temperature and dietary protein level on performance of multiparous lactating sows. Journal of Animal Science, v.79, p.1240-1249, 2001.
RICHERT, B.T.; GOODBAND, R.D.; TOKACH, M.D. et al. Increasing valine, isoleucine, and total branched-chain amino acids for lactation sows. Journal of Animal science, v.75, p.2117-2128, 1997.

ROSTAGNO, H.S.; ALBINO, L.F.T.; DONZELE, J.L. et al. Composição de alimentos e exigências nutricionais de aves e suínos: Tabelas Brasileiras. Viçosa, MG: UFV, 2005. 186p.

SILVA, B.A.N.; OLIVEIRA, R.F.M.; DONZELE, J.L. et al. Efeito do piso resfriado em maternidades para suínos sobre o desempenho produtivo e reprodutivo de porcas lactantes no verão - Parte I. In: CONGRESSO LATINO-AMERICANO DE SUINOCUlTURA, 2., 2004. Foz do Iguaçu. Anais... Foz do Iguaçu, 2004. p.300.

SPENCER, J.D.; BOYD, R.D.; CABRERA, R. et al. Early weaning to reduce tissue mobilization in lactating sows and milk supplementation to enhance pig weaning during extreme heat stress. Journal of Animal Science, v.81, p.2041-2052, 2003.

TOKACH, M.D.; PETTIGREW, J.E.; DIAL, G.G. et al. Characterization of luteinizing hormone secretion in the primiparous sows: relationship to blood metabolites and returnto-estrus. Journal of Animal Science, v.70, p.2195, 1992.

TOUCHETTE, K.J.; ALLEE, G.L.; NEWCOMB, M.D. et al. The lysine requirement of lactating primiparous sows. Journal of Animal Science, v.76, p.1091-1097, 1998.

UNIVERSIDADE FEDERAL DE VIÇOSA-UFV. SAEG - Sistemas de Análises Estatísticas e Genéticas. Versão 8.0. Viçosa, MG: 2000. 150p. 